\title{
Studievoortgangsproblemen van buitenlandse artsen die instromen in een hoger jaar van de opleiding geneeskunde
}

\author{
P.G.P. Herfs, J.R.E. Haalboom
}

\section{Samenvatting}

Buitenlandse artsen van wie de diploma's niet gelijkgesteld worden door de minister van VWS, vragen veelvuldig toelating tot medische opleidingen om in de toekomst in Nederland als arts te kunnen werken. In de laatste tien jaren hebben meer dan 1000 buitenlandse artsen via de Commissie Instroom Buitenlandse Artsen (CIBA) hiertoe een verzoek ingediend. In 2004 is berekend dat bijna 90\% van deze artsen feitelijk start met een aanvullende opleiding geneeskunde.

Daar er geen gegevens bekend waren over de voortgang van deze buitenlandse artsen in de aanvullende studietrajecten, is in dit onderzoek het studieverloop van alle 99 ingestroomde buitenlandse artsen in de cohorten 2002 en 2005 door de studieadviseurs geïnventariseerd. Gebleken is dat bij 38 studenten sprake was van studieproblematiek; de overige 61 studenten studeerden zonder problemen. De matige beheersing van de Nederlandse taal en de gebrekkige medische kennis en vaardigheden vormden de hoofdmoot van de problematiek. Ook werden attitudeproblemen vastgesteld. Naast de opleidingsgerelateerde problemen signaleerden de studieadviseurs ook problemen rond verblijfsstatus en levensfase (zoals studiefinanciering, huisvesting en zorg voor partner en/of kinderen). Opvallend was dat van de instroom in het cohort van $200271 \%$ een vluchtelingenstatus had, terwijl van de instroom in het cohort van 2005 het merendeel (57\%) in het kader van gezinsvorming in Nederland verbleef. De gemiddelde leeftijd bij de start van de aanvullende studie was 35 jaar.

Geadviseerd wordt om aandacht te blijven besteden aan de verbetering van de Nederlandse taal. Tevens is het van belang dat de expertise op het gebied van de begeleiding van buitenlandse artsen door studieadviseurs en studentendecanen niet verloren mag gaan. (Herfs PGP, Haalboom JRE. Studievoortgangsproblemen van buitenlandse artsen die instromen in een hoger jaar van de opleiding geneeskunde. Tijdschrift voor Medisch Onderwijs 2008;27(2):90-98.)

\section{Inleiding en vraagstelling}

Uit het buitenland afkomstige artsen kunnen niet zonder meer in Nederland het artsenberoep uitoefenen. Voor houders van binnen de Europese Economische Ruimte (EER) behaalde artsdiploma's zijn categorale erkenningsafspraken van kracht. ${ }^{1}$ De minister van VWS erkent echter de buiten de EER behaalde artsdiploma's veelal niet als gelijkwaardig. Dit artikel betreft artsen die niet beschikken over EER-artsdiploma's. Om in de toekomst in
Nederland als arts te kunnen werken is voor deze buitenlandse artsen een aanvullende medische studie noodzakelijk. Na het doorlopen van een voorbereidingstraject (cursus Nederlands en cursus medisch Nederlands) en toetsing van de achtergrond van de aanvragers, werd de afgelopen jaren een groot aantal artsen als student geneeskunde toegelaten tot de medische faculteiten (zie tabel 1).

De verdeling van buitenlandse artsen over de faculteiten vond plaats via de 
Tabel 1. Aantal aanvragen verdeeld door CIBA vanaf 1996.

\begin{tabular}{lcc}
\hline Jaar & $\begin{array}{c}\text { Aanvragen verdeeld } \\
\text { door CIBA }\end{array}$ & Cumulatief \\
\hline $1996 / 1997$ & 113 & \\
$1997 / 1998$ & 97 & 210 \\
$1998 / 1999$ & 127 & 337 \\
$1999 / 2000$ & 132 & 469 \\
$2000 / 2001$ & 136 & 605 \\
$2001 / 2002$ & 118 & 723 \\
$2002 / 2003$ & 126 & 849 \\
$2003 / 2004$ & 99 & 948 \\
$2004 / 2005$ & 83 & 1031 \\
$2005 / 2006$ & 40 & 1071 \\
\hline
\end{tabular}

Commissie Instroom Buitenlandse Artsen (CIBA), die in 1996 is ingesteld door het Disciplineoverlegorgaan Medische Wetenschappen (DMW). ${ }^{2}$ De aanpassing aan het Nederlandse systeem bleek de laatste tien jaren steeds moeilijker te worden. Dit liep ongeveer parallel aan een toenemende instroom van artsen uit Irak en Afghanistan. De tot dan toe gangbare procedures van inpassing leken niet meer te voldoen. Zowel problemen met betrekking tot de beheersing van de Nederlandse taal als met verschillen in culturele achtergrond manifesteerden zich steeds sterker. ${ }^{3}$ Dit was voor het DMW aanleiding om in 2001 een commissie in te stellen die de bouwstenen moest leveren voor een nieuwe VWS-assessmentprocedure. ${ }^{4}$ In december 2005 is deze nieuwe procedure in werking getreden. Vóór het van start gaan van de nieuwe procedure constateerden Haalboom et al. en Splinter et al. studievoortgangsproblemen bij instromende buitenlandse artsen/studenten. ${ }^{3-4}$ Tromp et al. publiceerden daarover na de invoering van de nieuwe procedure. ${ }^{5}$

De aard en de frequentie van de studievoortgangsproblemen van buitenlandse artsen waren niet eerder systematisch geïnventariseerd. In dit artikel wordt beschreven hoe frequent en welke studie- voortgangsproblemen ten tijde van de oude procedure voorkwamen in het eerste jaar van instroom van buitenlandse artsen in medische opleidingen, en in hoeverre deze bevindingen sporen met de nieuwe VWS-assessmentprocedure die vanaf december 2005 in werking is getreden.

\section{Methode}

Vijf medische faculteiten werden benaderd met het verzoek aan het onderzoek mee te werken. Er kon worden volstaan met vijf faculteiten aangezien verondersteld werd dat er weinig verschillen tussen de faculteiten bestaan ten aanzien van de opleiding van buitenlandse artsen. De overeenkomst tussen de faculteiten met betrekking tot de duur van de programma's die buitenlandse artsen moesten doorlopen, is voornamelijk gebaseerd op uitwisseling van ervaringen binnen de CIBA. Aan de deelnemers werd toegezegd dat in de rapportage niet bekend gemaakt zou worden welke faculteiten geparticipeerd hebben in het onderzoek. De lijst met participerende faculteiten is gedeponeerd bij de (voormalige) Rector Magnificus van de Universiteit Utrecht, prof. $\mathrm{dr}$ W.H. Gispen. Hierdoor kon gegarandeerd worden dat de privacy van de betreffende studenten niet geschonden werd. Deze garantie kon feitelijk alleen afgegeven worden als er ook faculteiten niet participeerden. Bij deelname van alle faculteiten zouden namelijk alle in 2002 en 2005 ingestroomde buitenlandse artsen terug te vinden zijn in de rapportage.

Aan de facultaire examencommissies werd toestemming gevraagd de dossiers te verzamelen van alle buitenlandse artsen die via de CIBA ingestroomd waren in de academische jaren 2002/2003 en 2005/ 2006. Per faculteit betrof het onderzoek 1530 artsen die voor het eerst als student geneeskunde ingeschreven werden tijdens de start van het academische jaar 2002 of 2005. 
Het cohort 2002 werd gekozen omdat dit het 'oudste' cohort was waarvan ten tijde van het onderzoek studentendossiers beschikbaar waren. Het cohort 2005 werd gekozen omdat dit het laatste cohort was dat geheel via de oude CIBA-procedure instroomde. Voor deze jaren werd bovendien gekozen omdat de instroom van buitenlandse artsen, als gevolg van de invoering van de Vreemdelingenwet in 2001, was gewijzigd. ${ }^{6}$ In 2002 betrof het vooral artsen met een vluchtelingachtergrond; in 2005 waren het met name gezinsvormers. Gezinsvormers zijn niet-Nederlanders die een verblijfsvergunning ontlenen aan het verblijf bij hun Nederlandse echtgenoot of partner.

De gegevens werden verkregen door dossieronderzoek. De dossiers werden onderzocht op de competenties die in de uiteindelijke VWS-assessmentprocedure zijn vastgelegd, volgend op het advies van de commissie Splinter. De studieadviseur van de betreffende faculteit onderzocht de dossiers van alle buitenlandse artsen op vastgelegde studievoortgangsproblemen. Met het oog op de privacy van de artsen had de onderzoeker geen directe inzage in de dossiers. Per faculteit en per student werden de in de dossiers vastgelegde studievoortgangsproblemen, zoals aangegeven door de studieadviseur, geïnventariseerd (zie box 1).

Ter controle werden van twee faculteiten 30 a-select gekozen dossiers van vijfdejaars 'reguliere' autochtone studenten geneeskunde onderzocht op aard en frequentie van studievoortgangsproblemen. Voor vijfdejaars studenten werd gekozen omdat deze studenten in een levensfase verkeren die meer overeenkomstig de levensfase was van de instromende buitenlandse artsen dan bij beginnende studenten het geval zou zijn. Op voorhand was bekend dat de vergelijking op onderdelen, die ontleend waren aan de VWS-assessmentprocedure, grote verschillen zou op-

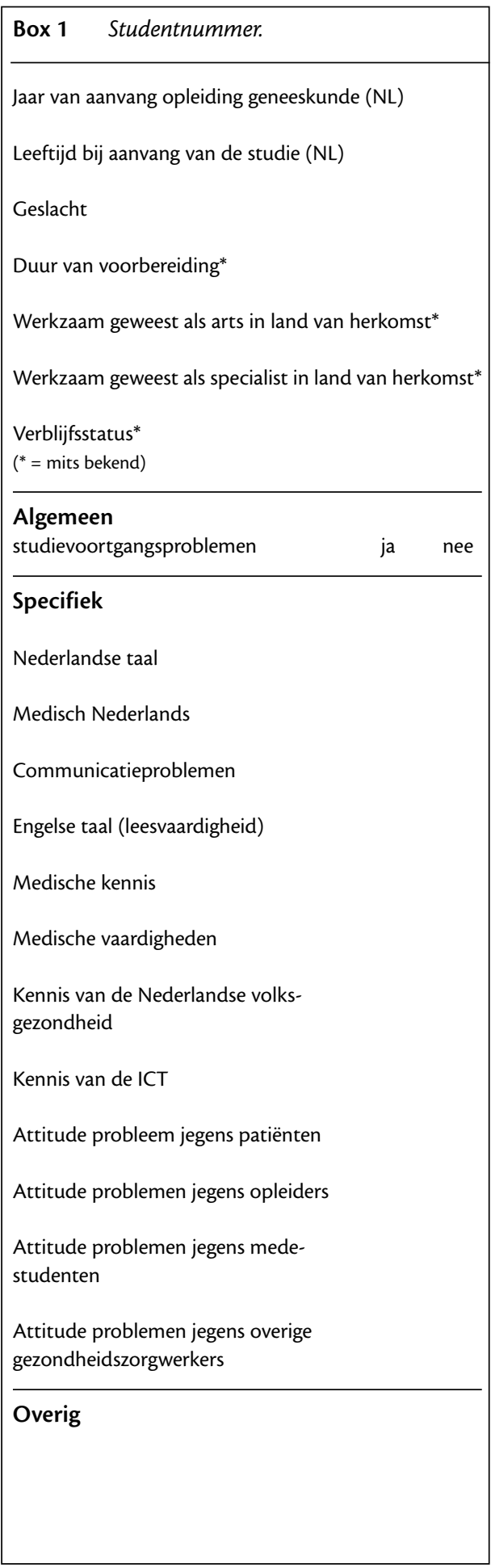


leveren. De beperkte gegevens van de controlegroep zijn niettemin vermeld om enig inzicht te geven in de aard en frequentie van studievoortgangsproblemen van 'reguliere' studenten.

Het onderzoeksmateriaal werd in de periode van maart tot september 2007 verzameld. De grootte van de steekproef was te gering voor statistische bewerking; de resultaten zullen beschrijvend weergegeven worden.

\section{Resultaten}

\section{Gesignaleerde problemen van studenten} uit een controlegroep

Uit 30 a-select gekozen dossiers van vijfdejaars 'reguliere' autochtone studenten geneeskunde van twee faculteiten bleek dat er bij tien studenten sprake was van

Tabel 2. Gesignaleerde problemen bij 30 autochtone studenten uit controlegroep.

\begin{tabular}{lc}
\hline Aard van probleem & 2005 \\
\hline Gezondheidsklachten van student, & \\
partner of kind & 6 \\
Medische kennis & 2 \\
Studieplanning & 2 \\
\hline Totaal & 10 \\
\hline
\end{tabular}

studievoortgangsproblemen. Zie voor de gescoorde categorieën tabel 2 .

\section{Algemene resultaten}

De algemene gegevens over de onderzochte buitenlandse artsen in de jaren 2002 en 2005 zijn weergegeven in tabel 3.

Het aantal vrouwen is in 2005 toegenomen en een ruime meerderheid heeft werkervaring als arts. De gemiddelde leeftijd was bij aanvang van de opleiding geneeskunde 35 jaar. Een verschuiving trad op in de verhouding vluchteling-gezinsvormer.

\section{Studievoortgangsproblemen}

Tabel 4 toont het aantal studenten met studievoortgangsproblemen. In 38 dossiers werden studievoortgangsproblemen gesignaleerd. In 2002 betrof dit 44\% en in 2005 betrof dit $32 \%$ van de studenten.

In tabel 5 zijn de verschillende studievoortgangsproblemen per cohort in kaart gebracht. Alle studievoortgangsproblemen werden gescoord; bij een aantal studenten was er sprake van meervoudige problematiek. In 2002 betrof het 38 problemen; in 2005 werden 36 problemen gesignaleerd. In totaal betrof het 74 problemen bij 38 studenten.

Tabel 3. Algemene gegevens van de onderzoekspopulatie.

\begin{tabular}{lcccccc}
\hline & \multicolumn{2}{c}{2002} & \multicolumn{2}{c}{2005} & & $2002+2005$ \\
\hline & $n$ & $\%$ & $n$ & $\%$ & $n$ & $\%$ \\
Totaal & 52 & & 47 & & 99 & \\
$\quad$ Man & 25 & 48 & 16 & 34 & 41 & 41 \\
$\quad$ Vrouw & 27 & 52 & 31 & 66 & 58 & 59 \\
Werkervaring als arts & 43 & 83 & 38 & 81 & 81 & 82 \\
Geen werkervaring & 8 & 15 & 9 & 19 & 17 & 17 \\
Werkervaring als specialist & 15 & 29 & 21 & 45 & 36 & 36 \\
Verblijfsstatus als vluchteling & 37 & 71 & 20 & 43 & 57 & 58 \\
Verblijfsstatus als gezinsvormer & 15 & 29 & 27 & 57 & 42 & 42 \\
\hline
\end{tabular}


Tabel 4. Studievoortgangsproblemen in 2002 en 2005.

\begin{tabular}{lllllll}
\hline Studievoortgangsproblemen & \multicolumn{2}{c}{2002} & \multicolumn{2}{c}{$\mathbf{2 0 0 5}$} & \multicolumn{2}{c}{$\mathbf{2 0 0 2 + 2 0 0 5}$} \\
\hline & $\mathbf{n}$ & $\%$ & $\mathbf{n}$ & $\%$ & $\mathbf{n}$ & $\%$ \\
$\mathrm{Ja}$ & 23 & 44 & 15 & 32 & 38 & 38 \\
Neen & 29 & 56 & 32 & 68 & 61 & 62 \\
\hline Totaal & 52 & & 47 & & 99 \\
\hline
\end{tabular}

Tabel 5. Aard van de studievoortgangsproblemen in 2002 en 2005.

\begin{tabular}{lll}
\hline Aard van de problematiek & 2002 & 2005 \\
\hline Nederlandse taal & 6 & 8 \\
Medisch Nederlands & 0 & 2 \\
Communicatieproblemen & 4 & 4 \\
Engelse taal (leesvaardigheid) & 4 & 3 \\
Medische kennis & 13 & 5 \\
Medische vaardigheden & 3 & 3 \\
Kennis van de Nederlandse volksgezondheid & 0 & 0 \\
Kennis van de ICT & 1 & 2 \\
Attitudeproblemen jegens patiënten & 2 & 3 \\
Attitudeproblemen jegens opleiders & 1 & 4 \\
Attitudeproblemen jegens medestudenten & 1 & 1 \\
Attitudeproblemen jegens overige gezondheidszorgwerkers & 0 & 1 \\
Beperkte studievaardigheden & 1 & 0 \\
Faalangst & 2 & 0 \\
\hline Totaal & $38(\mathrm{n}=23)$ & $36(\mathrm{n}=15)$ \\
\hline
\end{tabular}

\section{Bijkomstige, niet studiegerelateerde problemen}

In de categorie 'overig' werden diverse problemen nader gespecificeerd (zie tabel 6). Het betreft een opsomming van alle gevonden problemen bij alle studenten uit het cohort. Meerdere scores per student waren mogelijk.

\section{Discussie}

In dit onderzoek zijn studievoortgangsproblemen van twee cohorten buitenlandse artsen tijdens hun jaar van in- stroom in een medische opleiding op systematische en kwantitatieve wijze geïnventariseerd. De onderzoeken van Splinter et al. (2003) en van Tromp et al. (2007) waren kwalitatief van aard en gaven een inventarisatie van de aard van de studievoortgangsproblemen.

Sinds december 2005 wordt bij de inpassing van buitenlandse artsen gebruik gemaakt van een nieuwe assessmentprocedure. Er wordt getoetst op algemene kennisonderdelen (Nederlands, Engels, ICT, enz.) en op medische kennis en vaar- 
Tabel 6 Bijkomstige, niet studiegerelateerde problemen.

\begin{tabular}{lcc}
\hline Aard van probleem & 2002 & 2005 \\
\hline Financiële zorgen vanwege problemen met Sociale Dienst & 4 & 2 \\
Hoge reiskosten en/of lange reisafstand naar universiteit & 1 & 3 \\
Onzekerheid over verblijfsstatus & 3 & 1 \\
Oorlogstrauma's & 2 & 1 \\
Ernstige gezondheidsklachten van student, partner of kind & 5 & 7 \\
Combinatie van studie met gezinstaken & 1 & 3 \\
Huisvestingsproblemen & 1 & 3 \\
Problemen met inpassing en/of toetsing & 1 & 1 \\
Problemen met dialect sprekende patiënten & 1 & 0 \\
Aanloopproblemen/gewenningsproblemen & 0 & 2 \\
\hline Totaal & $19(\mathrm{n}=52)$ & $23(\mathrm{n}=47)$ \\
\hline
\end{tabular}

digheden. Uit het huidige onderzoek blijkt dat de geïnventariseerde studievoortgangsproblemen grotendeels overeenkomen met de competenties van de VWSassessmentprocedure.

In 2002 en 2005 werden in totaal 99 buitenlandse artsen toegelaten tot de vijf medische faculteiten; allen participeerden in dit onderzoek. In deze jaren heeft een verschuiving plaats gevonden in de richting van artsen die als gezinsvormers in Nederland verblijven. Na bestudering van de studentendossiers bleek dat in totaal $38 \%$ van de buitenlandse artsen in 2002 en 2005 studievoortgangsproblemen ondervonden heeft. Problemen deden zich zowel voor met betrekking tot de Nederlandse taal, medisch Nederlands en communicatie als met de medische kennis en vaardigheden: in beide categorieën 24 keer (32\%). Vergelijking met studentendossiers van een controlegroep van vijfdejaars 'reguliere' studenten geneeskunde leerde dat van deze autochtone studenten 33\% contact heeft gezocht met studieadviseurs. Hun problemen hebben voornamelijk te maken met gezondheidsklachten.

De gevonden problemen ten aanzien van de Nederlandse taal komen overeen met resultaten uit eerder onderzoek. ${ }^{7-8}$ De facultaire studieadviseurs benadrukten de verschillen tussen gezinsvormers en asielzoekers/vluchtelingen (met of zonder gezin). De eerste categorie leert sneller en beter Nederlands dan de tweede categorie. Een mogelijke verklaring is dat vluchtelingen in de privésituatie veel minder intensief met de Nederlandse taal in aanraking komen.

Problemen ten aanzien van de medische kennis werden 18 keer (24\%) vermeld. Dit relatief hoge aantal kan beïnvloed zijn door het feit dat 36\% van de buitenlandse artsen in eigen land al werkzaam was als specialist en bij de toetsing vooral is ondervraagd op algemene medische basiskennis, die op de achtergrond kan zijn geraakt. Attitudeproblemen jegens patiënten, opleiders, medestudenten en overige gezondheidszorgmedewerkers werden 13 keer $(18 \%)$ gerapporteerd. In de studentendossiers werden 42 keer 'bijkomstige problemen' gesignaleerd, die vooral samenhangen met de levensgeschiedenis en verblijfsstatus.

De gemiddelde leeftijd was 35 jaar. Dat betekent dat het merendeel niet meer in aanmerking kwam voor studiefinancie- 
ring van de Informatie Beheer Groep. Financiering van de aanvullende studie moet dan via andere kanalen (bijvoorbeeld via de Gemeentelijke Sociale Dienst, via de Stichting voor Vluchtelingstudenten UAF of via een partner) worden geregeld. Daarnaast hebben deze studenten vaak al de zorg voor een gezin. De combinatie van een medische opleiding met gezinstaken levert op beide fronten problemen op.

Vluchtelingstudenten worden verder geconfronteerd met extra problemen als beperkte mogelijkheden tot voorbereiding op de studie, onzekerheid over de verblijfsstatus, gebrekkige financiële middelen, huisvesting op grote(re) afstand van de medische faculteit, geen studiefinanciering, geen OV-jaarkaart, enz. Voor begeleiding kunnen buitenlandse artsen/ studenten terugvallen op de studieadviseurs of studentendecanen van de universiteiten.

\section{Conclusies}

De meerderheid van de instromende buitenlandse artsen (62\%) studeert zonder problemen aan de bij dit onderzoek betrokken medische opleidingen. Bij de resterende $38 \%$ van de buitenlandse artsen die in 2002 en 2005 gestart waren met hun aanvullende opleiding zijn wel problemen gesignaleerd. Het betrof vooral problemen met de Nederlandse taal, medische kennis en vaardigheden.

Deze resultaten bevestigen de uitkomsten van voorgaande studies en onderstrepen het belang van permanente aandacht voor verbetering van het beheersingsniveau van de Nederlandse taal tijdens de aanvullende opleiding geneeskunde. 358 Beheersing van de Nederlandse taal is onontbeerlijk voor het adequaat functioneren in de Nederlandse gezondheidszorg. De Nederlandse taal vormt een groot struikelblok voor buitenlandse artsen. Het blijkt dat de aanvullende opleiding geneeskunde vooral is gericht op de lacunes in medische kennis en vaardigheden.

De buitenlandse artsen worden tijdens het opleidingstraject ook beoordeeld op professioneel gedrag jegens patiënten en collegae. Het is van groot belang dat attitudeproblemen tijdens de aanvullende opleiding bespreekbaar gemaakt worden en vervolgens adequaat worden opgelost. Dit sluit aan bij het advies dat een VSNUwerkgroep over deze specifieke problematiek heeft uitgebracht. ${ }^{9}$

Buitenlandse artsen zijn geen 'doorsneestudenten'. Ze hebben niet alleen buitenlandse artsdiploma's, maar zijn minstens tien jaar ouder en verkeren in andere levensfases dan de meeste 'reguliere' studiegenoten. Onder hen bevinden zich studenten met oorlogstrauma's, studenten die gezin en studie combineren, studenten met verblijfsvergunningsproblemen, studenten die problemen hebben met de Gemeentelijke Sociale Dienst, enz. Hun geschiedenis als vluchteling of migrant is van invloed op hun studieloopbaan aan een medische faculteit.

Sinds de jaren negentig zijn buitenlandse artsen met ongelijkwaardige diploma's als studenten in een hoger jaar van de opleiding geneeskunde ingestroomd. Medische opleidingen zien zich dan ook geplaatst voor andere problemen dan voorheen.

Sinds de oprichting van de CIBA in 1996 was aan iedere medische faculteit een portefeuillehouder (meestal een studieadviseur) belast met de inpassing en begeleiding van buitenlandse artsen. In september 2007 is de CIBA als gevolg van de invoering van de nieuwe VWS-assessmentprocedure opgeheven. Hoewel de aantallen instromende buitenlandse artsen sinds de invoering van de assessmentprocedure zijn teruggelopen, is de noodzaak om aan medische opleidingen een 
passend begeleidingsaanbod te kunnen bieden niet minder geworden. Het is van groot belang dat de expertise in de begeleiding van buitenlandse artsen behouden blijft.

\section{Literatuur}

1. Directive 2005/36/EC of the European Parliament and of the Council of 7 September 2005 on the recognition of professional qualifications. Brussels, Belgium; 2005.

2. Herfs PGP: Erkenning van buitenlandse artsdiploma's; een verhaal apart. Utrecht: afdeling Studentenzaken, Universiteit Utrecht; 1996. [Recognition of foreign medical degrees; a different story. Utrecht: Department of Student Affairs; 1996].

3. Haalboom JRE en Herfs PGP: De inpassing van buitenlandse artsen in het Nederlandse medische curriculum. Medisch Contact 1998;53: 44. [Fitting foreign doctors into the Dutch medical curriculum. Medical Contact 1998;53:44].

4. Splinter TAW, Herfs PGP, Ruijs AJEM, Luijk SJ van, Wijkhuijs NP: Naar een nieuwe stroomlijn voor buitenlandse artsen; een rapport van de Opleidingscommissie Geneeskunde van het Disciplineoverlegorgaan Medische Wetenschappen (OCG-DMW); 2003. [Towards a new streamline for foreign doctors; report of the Medical Education Committee of DMW, Association of Universities in the Netherlands; 2003].

5. Tromp F, Rademakers JJDJM, Ten Cate ThJ: Development of an instrument to assess professional behaviour of foreign medical graduates. In: Medical Teacher 2007; 29(2\&3):150-5.

6. Staatsblad, 495: Vreemdelingenwet 2000. Sdu; 2001. [Bulletin of Acts, Orders and Decrees, 495: Immigration law 2000, Sdu; 2001].
7. Haalboom JRE en Herfs PGP: Utrecht ontwikkelt module voor bijscholing buitenlandse artsen. Transfer 1999;6 (7). Nuffic, Den Haag; 1999. [Utrecht is developing a module for continuing professional development of foreign medical graduates. Transfer 1999;6(7)].

8. Herfs PGP: Is Nederland toe aan een Nt2-examen programma 3? In: Schoordijk FMC en TaalApelqvist L (redactie): Nederlands leren na het Staatsexamen Nt-II. Symposiumbundel ter gelegenheid van het afscheid van Hans Maureau van het INTT. Universiteit van Amsterdam; 2006. [Are the Netherlands in need of exam programma 3 for Dutch as a foreign language? In: Learning Dutch after the state exam NT-II. Papers presented at the symposium in honour of Hans Maureau, INTT, University of Amsterdam].

9. Projectteam Consilium Abeundi: Professioneel gedrag; onderwijs, toetsing, begeleiding en regelgeving. Eindrapport en bijlagen. In opdracht van de VSNU, Utrecht; 2002. [Project Team Consilium Abeundi appointed bij DMW (VSNU). Professional behaviour; teaching, assessing and coaching students. Final report. Utrecht; 2002].

\section{De auteurs:}

Drs. P.G.P. Herfs was als studentendecaan betrokken bij de oprichting van de CIBA en tot aan de opheffing ervan adviserend CIBA-lid.

Prof. dr. J.R.E. Haalboom is internist in het UMC Utrecht.

Correspondentieadres:

Drs. P.G.P. Herfs, Bureau van de Vertrouwenspersoon, Universiteit Utrecht, postbus 80148, 3508 TC Utrecht. Tel.: 030-2539988; email: p.g.p.herfs@uu.nl

Belangenconflict: geen gemeld.

Financiële ondersteuning: geen gemeld.

\section{Summary}

In the last decade more than 1000 foreign medical graduates, whose medical degrees are not recognised by the Dutch Department of Health, applied for admittance to medical schools in the Netherlands. Some 90\% of them were actually admitted. Study problems of foreign medical graduates during their additional medical training in the Netherlands have not been studied systematically.

We made an inventory of the types of problems and the frequency of their occurrence for all 99 foreign medical graduates entering five Dutch medical schools in 2002 and 2005 as reported by the study advisors. Problems were reported for $38 \%$ of the foreign graduates, while the majority (62\%) had no problems. Language problems and problems related to deficiencies in medical knowledge and skills were reported most frequently. In 2002, the majority (71\%) of foreign medical graduates had a background as a refugee, while in 2005 the majority (57\%) had a visa to stay with their spouses or partners. Apart from study-related problems, there were also problems related to the phase of life of the students, whose average age on entering medical school was 35 years, such as problems in obtaining a study grant, housing problems and the responsibility for a partner and/or children. Continuous attention for mastery of the Dutch language is important. Furthermore, counselling expertise relating to foreign medical graduates should be maintained among study advisors in order to meet the specific needs of these students. (Herfs PGP, Haalboom JRE. Problems relating to study progress of foreign medical graduates at Dutch medical schools. Dutch Journal of Medical Education 2008;27(2):90-98.) 